\title{
Deconstructed Language in Higher Education Deconstructing Science
}

\author{
A. Beatriz Pérez-González \\ Department of General Economy, Faculty of Educational Sciences, Campus of Puerto Real, University of Cádiz, Spain
}

Copyright@2019 by authors, all rights reserved. Authors agree that this article remains permanently open access under the terms of the Creative Commons Attribution License 4.0 International License

\begin{abstract}
The present study examines university students' perceptions of learning academic terminology and using specialised language, and discusses the consequences of their vision. The aim is to elucidate the relationship between academic culture, academic education and the construction of knowledge in higher education. The fields of meaning and the level of difficulty entailed in understanding technical or specialised content in the context of our students (L2) are associated with the current context and widespread use of technological devices. The lack of command of fields of meaning not only impedes the construction of new theoretical models, but also increasingly differentiates between groups, widening the gap between students who possess more specialised codes and those who do not.
\end{abstract}

Keywords Scientific Construction, Language and University Students, Student Discourse Codes, Communication and Language

\section{Introduction}

The main problem that prompted the present study was how to improve understanding of specialised subjects on university courses. An analysis of language and communication emerged as a fundamental means to achieve this. An earlier paper (Imperfect Language, presented at the International Science and Technology Conference, Rome, June 2013) has highlighted the difficulties inherent in this area.

Students in higher education appear to experience structural difficulties in acquiring and assimilating academic terminology.

In the present study, we work the social dimension of language and culture, the academic skills deployed in a university and the specialist language.

\section{Background}

Several different approaches can be taken to the analysis of knowledge of terminology; for the present study, a socio-cognitive rather than sociolinguistic perspective was adopted. For example, what does a university lecturer do? He or she explains the meanings of the terms that appear in specialised theories and texts. According to Montero Martinez (2002)3 "Standardisation is only one facet of the study of terminology and although it is necessary, it is misguided to argue that the principles governing this type of prescriptive terminological work constitute the principles of a general theory of terminology, as this latter plays a major role in many other socio-cognitive and communicative situations”.

Research on the subject has adopted overlapping anthropological, sociolinguistic and linguistic approaches. In the 1960s, some very interesting studies were conducted on language and its uses, and these continued into the following decade. Ethnographic observation comprises a suitable method for such studies, as does reference to the ethnography of speaking and communication (EC), an approach proposed by Dell Hymes in 19624 which examines the uses of language in everyday life within a speech community.

The social dimension of language and culture is of interest because it determines the uses of communicative conditions, since language reflects a speech community's values. Note in this regard the study by Byram (1997)5.

In the present study, academic language or academic discourse was considered in the sense used by López Pérez, M. V., (2004) 6 to elucidate multiple questions in the group-class related to the academic skills deployed in a university. In teaching-learning situations, the use of spoken or written language is the product of specialised communication. It can also be conceptualised as a specialist language (Christ, H. 1996) 7, whether in terms of a scientific study or the intellectual effort required for some professions 
A group's "voices” could be classified according to frequency and distinction with regard to specialised terminology. However, this aspect is further complicated if it is influenced by the special linguistic features of a cultural community. Therefore, any study should consider the traits that characterise the group: their socio-economic and geographical origin. A group-class can be considered a specific community, forming an ethnographic and cultural context marked by characteristics inherent to the speech of a given geographical space.

To speak of a specific community (Gumperz, 1968, p. 381-386)8, one must make reference to the contexts in which the interaction takes place (with shared meanings), income level and geographical space.

One aspect that complicates terminology work in class is the "multifaceted nature of terminological units". According to Cabré (2009)9, terms encompass cognitive, linguistic, and social components. Experts use terms to communicate among themselves, but at the same time, they also serve to train new experts and convey specialised knowledge. Our students will become experts in education, and their knowledge should therefore attain a specialist level. Besides being a resource employed for communication, terminology provides specific meanings, without which knowledge could not be so specialised.

The challenge for teachers in present-day society is how to inculcate appropriate academic language and design techniques that help students use elaborated codes rather than simple or baroque language that is biased, unscientific, replete with inaccuracies and does not inspire innovative strategies or change applicable to other fields. As regards a speaker's general and specialised competence, outside the communicative context, some lexical units are neither words nor terms. They are instead referential units (Cabré, 199)10. The present study concerns precisely these units.

Besides the terminological deterioration and use of unacademic categories inherent to a less specialised code, there is also the use of language derived above all from technology. These uses and languages undermine the validity of the categories of academic or scientific analysis. There are certain methodological strategies to tackle this. Cabero, J. and Gisbert, M. (2005)11 have suggested two techniques. The first is to use internet or visual teaching resources that distil the elements necessary for education but do not incorporate others that distract from this. From a conceptual point of view, these resources should incorporate the most significant semantic fields in the education-information environment, leaving additional information for further enquiry and expansion. The other technique they suggest is to prioritise teaching over technology, in order to avoid information that distracts students.

Reflection on these issues is prompted by the questions that all teachers ask themselves at the end of their courses: have the tools used in class facilitated specialised learning? Have the students acquired the skills to construct arguments? And what results have been achieved?

\section{Case Study}

Through technology, students generalise new fields of meaning or expand meaning. The use and modification of fields of meaning is directly related to scientific level and should be introduced by the teacher. Furthermore, it is influenced by the technological level, habits and future of the social group in question: all human groups develop exactly the language of culture, technology and economy that they have heard from birth, although they also expand on and develop this according to prevailing values and fashions.

In light of this, what changes have occurred today in the textuality of the teaching paradigm as formulated by Toschi (2012)? ${ }^{12}$ For example, has this technological change heightened the differences between the mode of speech in the group-class (even though the students have lived through these changes) $?^{13}$ When students study, the words that they underline in a text are related to their conceptual maps, and their summaries to series of signifiers. If students do not habitually summarise what they have learnt, or do not know how to do so because they have not understood part of the series of concepts, they will need new learning techniques because the language they are using may impede subsequent specialised use. Students may also experience problems in this respect. Similarly, as mentioned earlier, a geographical linguistic specificity may hinder the development of more elaborated linguistic codes because expressive traits combined with a specific syntax, with characteristics of a geographical nature, can also contribute to the use of unspecialised terminology. As indicated by Payán Sotomayor ${ }^{14}$, specific grammatical constructions hinder more specialised use. Many voices find their meaning in culture and geographical or organisational aspects (related to the climate or other invented reasons that have subsequently become widespread at national level, metaphorical comparisons or references that are related to situations or street names or make reference to songs), and are reflected in a particular vision of things.

Technological changes have also left their mark on semantics. As the use of the new information and communication technologies has become increasingly widespread, we have varied, adapted and modified our everyday and academic expression. Thus, many terms may come to represent difficult fields of meaning for certain students, in other words, they may become terms with which students do not identify because they form part of a more academic and specialised use. Not identifying with the academic corpus also distances students from specialised academic and professional culture. As this occurs or becomes widespread, teachers begin to use simpler analogies, which essentially contain images, in 
order to render knowledge more accessible to their students. This means that the latter acquire lower levels of understanding and therefore have fewer future prospects.

How can this be applied to transforming the code of teachers' medium of communication? Is it possible to unite the more visual language that prevails today with a more elaborated, specialised language? The fundamental concept refers to language and its application to the world of teaching-learning methodology. This concept of methodology (applying the study by McLuhan, 2002, p. $91)^{15}$ could imply the possibility of approaching methodology as if one were completely free of any social or moral responsibility.

Images and more visual content are analogies that form the bulk of students' language these days; these analogies are not specialised, given their widespread use, and constitute a less elaborated code. However, they are transferred from everyday to academic life. This shift can have other consequences for the students, both in class and in their professional careers, and may also have repercussions for the future state of academia and even science.

\subsection{Materials and Method}

In the present study, data were collected using quantitative and qualitative tools. As regards the study participants and setting (two of the components of speech discussed by Hymes in 1967) ${ }^{16}$, the former consisted of students of L2, while the latter was a sociology course for teacher training students in their first and fourth years of university. Two approaches were employed:

a) A questionnaire was administered to students $(\mathrm{n}=100)$ to elucidate their perceptions of the construction of theoretical arguments. This instrument consisted of questions aimed at detecting the importance students gave to the correct use of language and the use of scientific terminology. The study subjects in this group were final year undergraduate students, all of whom were women: $63 \%$ were aged between 21 and 23 years old and $37 \%$ between 25 and 27 .

b) In addition, as an experiment, another group of students was asked at the end of their academic year to list the concepts they considered were the most specialised in the subject. Half of them mentioned a high number of concepts. In order to determine whether the number of terms they named was related to a better grasp of theory, a comparison was conducted between the number of terms listed and the marks obtained in theoretical tests. The subjects who participated in part b) of the study were first year students mostly aged between 18 and 20 years old.

Thus, the study subjects who participated in part a) of the study were students (mainly women) in their final year, of whom $63 \%$ were aged between 21 and 23 years old and $37 \%$ between 25 and 27 . The age profile of the students was therefore somewhat older than average and some already had another qualification. Most had specialised in the humanities at high school, but a substantial number of female students had studied advanced technical courses or modules unrelated to education (e.g. dental hygienist). Some also had qualifications in early childhood education. They were attending a public university and their families had a medium or low income level. Few of the students were employed in paid work. They came from Jerez, the Sierra of Cadiz, San Fernando, Chiclana and other towns (students from other Autonomous Regions or participating in a student mobility programmers were poorly represented in the sample).

As regards the setting, classrooms at the university had been adapted for the use of computers in teaching between the late 1990s and 2000. Prior to that, teaching staff had used traditional blackboards and audio-visual media such as transparencies, but afterwards they steadily adopted the use of computers; nowadays, $90 \%$ of teachers use technology, programs such as Prezi or Power Point and internet videos for presentations in both practical and theoretical classes. Thus, although accompanied with explanations, the use of these tools has implied an increasing visual load. Teaching assessments since then have not suggested any other technological changes in teaching.

In the present study, quantitative and qualitative tools were used to collect data. A questionnaire was administered to a total of 100 students to determine their perceptions regarding the construction of theoretical arguments.

The questionnaire consisted of closed questions with binary or multiple choice response options. It also included control questions to identify possible response errors. In addition, as an experiment at the end of the academic year, first year students were asked to list the concepts they thought were most specialised in the subject. Half of them mentioned a high number of concepts. To determine whether the number of terms they named was related to a better grasp of theory, a comparison was conducted between the number of terms listed and the marks obtained in theoretical tests. These two measurement instruments (the questionnaire and an experiment to measure scientific concepts) were applied to students in different years (first and fourth years), with the aim of obtaining information about students' perceptions and progress regarding the correct use of concepts and specialised learning.

To present the questionnaire results as percentages, the proposed indicator for their status regarding the correct use of spoken and written language was a response percentage scale (taking into account the response options available), as follows:

1. Not very satisfied $>80 \%$ Critical status

2. Completely satisfied $>80 \%$ Differential and competitive success

3. Very satisfied $<30 \%$ High risk status 


\subsection{Results}

As previously mentioned, to obtain a sufficiently significant variation in responses, different forms of measurement were used: a) students' perceptions of their own level of spoken and written language, and b) consideration of an elaborated code with fields of meaning. With regard to the questionnaire, the percentages for options 1 and 2 (level of satisfaction) were 18\% (not very satisfied), $43 \%$ very satisfied and 39\% (completely satisfied), respectively; thus, none of the participants presented a critical status or differential and competitive success. Neither did they present a high risk status (option 3 ), since they attained $43 \%$. This indicates that the students (at higher education level) did not present an extreme status according to their own perceptions, but neither did they excel in a precise, elaborated code in academic speech and writing.

Hence, the questionnaire results suggest that the students were aware of the importance of the correct use of language and the use of appropriate terminology. They also indicate that the students considered themselves to have sufficient command of both colloquial and academic language.

With regard to the experiment conducted in class at the end of the year (aspect b), in which students were asked to list the scientific and academic concepts that they had mastered, the results were very interesting. Contrary to expectations, there was no evidence that students cited a smaller number or scarcity of fields of specialised meaning, since they listed a high number of specialised terms. Does this indicate that teaching staff are mistaken in thinking that academic language is rarely used correctly? What is true is that the number of fields of meaning did not have a direct correlation with the acquisition of elaborate academic knowledge. To use the analogy of learning a language, the higher the number of words or terms at one's command, the better the chance of expressing oneself using a more elaborate corpus; the same may well be true of the construction of academic knowledge. If academic knowledge cannot subsequently be used to construct a discourse, there is no application or result. However, as we can see, the unexpected occurred. This is because naming is not the same as constructing knowledge. Thus, even though the students may remember specialised terminology, if their command of it is poor or they are unable to use it in coherent discourse, their learning will not result in specialisation or the necessary scientific construction.

To conduct a more detailed study, the number of concepts they named was related to the marks they achieved. The following categories were established according to the number of concepts cited:
1. Between 5 and 7
2. Between 8 and 10
3. Between 11 and 15
4. More than 15

These were compared with the marks obtained in tests, divided into three categories: a mark higher than or equal to 6 (good pass), a mark between 5 and 5.9 (pass) and a mark equal to or less than two (fail). Note that the classes and tests were aimed at eliciting authors and theories, which together form the foundation of new constructions. It was therefore one of the objectives of the subject the students were studying.

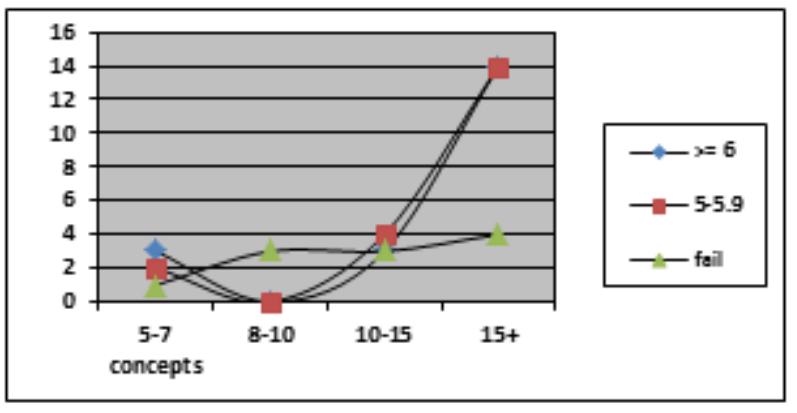

Source: by the author

Figure 1. Results of a comparison of marks and number of concepts

A relationship was observed whereby the higher the number of concepts named, the higher the mark students obtained in the test. Although many of the students who failed the test could name concepts, the academic level displayed in their test was unsatisfactory for a university course.

To construct knowledge satisfactorily, students need to possess resources in oral and written language. A command of this language not only forms part of academic culture but is also the foundation for constructing new academic and scientific discourse. However, the students' grasp of both the lexicon and the textuality of this code was inadequate.

Many of the students had not assimilated these specialised terms consistently in their discourse. Very few of the final year students who completed the questionnaire had assimilated a more elaborated code into their discourse, either. This was evident from a qualitative assessment of their work, where only $5 \%$ of the class employed more elaborated academic terminology. This is disappointing.

Continuing with the questionnaire, students agreed that it was important at all educational levels to learn and use written and spoken language correctly (99\%) and considered that medium level use evidenced satisfactory learning (86\%). Over half (67\%) considered an academic level use of language "essential", but 94\% thought that it led to lack of understanding in questions at a higher academic level (items 9 and 8, respectively). In addition, for the majority (90\%), possessing a command of specialised registers was crucial to acquire knowledge of the subject.

The students indicated that examples of misunderstanding terms and incorrect use of concepts occurred in several contexts: 


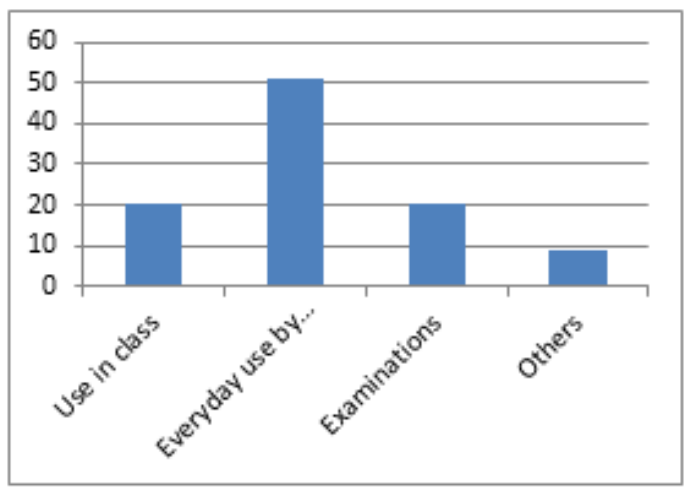

Source: compiled by the author from questionnaires

Figure 2. Contexts by percentage of examples of misunderstanding terms and incorrect use according to students

The responses evidenced a high number of restricted codes, which are shared by students in everyday use. This was to be expected, but clearly highlights the prevalence of a common culture with little interest in the academic register. The results to the question on how to penalise errors showed that only $3 \%$ believed that these should affect their marks. Meanwhile, 13\% suggested that corrections should be given verbally (which is what teachers do every day in their classes), $5.1 \%$ thought that other tasks should be given and another $5.1 \%$ said that this depended on the error.

According to $49 \%$ of students, language use errors were caused by habitual use of modern technologies, while $43 \%$ thought they were due to the negligible importance accorded to language and knowledge (43\%). They did not think that the use of youth slang contributed significantly to a deterioration in the code they use. Almost half (45\%) thought that spelling errors were rare among their peers and that correction was mainly the responsibility of the individual student. It is significant that they gave little importance to the role of institutions in improvement. For this question, students were given several response options, and after the above response, in order from most to least importance, they indicated that correction was the responsibility of teachers, followed by parents and lastly (16\%) institutions. However, this question can be compared to item 2, which asked students who they thought was responsible for the correct use of spoken and written language. In this case, not all students selected several options, and most (67\%) indicated that this was the responsibility of teachers; only $16 \%$ thought it was the responsibility of students themselves while $27 \%$ declared that it was only partially the responsibility of teachers. The discrepancy between responses for similar questions such as items 2 and 18 indicated that they were unable to accurately identify who was ultimately responsible for errors. However, item 18 was a control question, and the higher number of response options selected when completing the questionnaire indicates that they were more interested in apportioning responsibility between all actors.

A total of $57 \%$ considered that incorrect use impeded assimilation of subject content while only $12 \%$ thought that it prevented scientific academic construction and 31\% believed that it prevented construction of new knowledge. In other words, $43 \%$ agreed that possessing a command of academic terminology was related to scientific aspects and the construction of new knowledge. This question suggests that the students did not always relate the more elaborated code to the acquisition of scientific and theoretical knowledge. However, in a more direct question (item 15), $57 \%$ felt that there was a relationship between the correct use of written language and the scientific skill of observation, whereas only $6 \%$ did not think such a relationship existed and 37\% thought there was only a partial relationship. Thus, according to the students, possessing a command of the scientific terminology of a subject was related to the creation and construction of new models (74\%), the construction of theoretical models (13\%) and the construction of practical models (8\%). Only 5\% responded negatively, considering that it was unrelated to the construction of theoretical or practical models.

All of the students $(100 \%)$ reported that none of the teachers they had had until then had designed strategies to improve elaborated use or better language skills, although as their responses to item 18 showed, a large number of them thought that this was the teacher's responsibility. In sum, they did not consider that suitable methods were employed in class to help them learn and master the terminology associated with the subjects taught. This aspect is also very disappointing, and teaching staff should be given pause for thought.

\section{Conclusions}

With reference to the criticisms of impenetrable jargon or the power and prestige that distinguish groups that use a specialized language, the present study did not aim to differentiate modern and specialized (such as academic) uses of language, but rather facilitate the use in educational environments of the most expert and careful language required by the scientific community, to achieve an accurate and unambiguous expression of the concepts.

The traits inherent to specific languages have been defined in the literature, but the critical study of groups and class, such as the research conducted by Willis, P. or Bernstein B., among others, has been abandoned. Even less research attention is paid to the relationship between specialist vocabulary and group-class vocabulary.

Both the contribution of Willis (1986) $)^{17}$, concerning cultural production, the meaning people give it and the relationship with academic achievement, and the study by Bernstein ${ }^{18}$ on terminology use and students' habituation to restricted codes, could be applied to higher education today. However, this area of research seems to have lost its appeal, having begun to fade away in the late 1980s. One of today's challenges therefore is to revive research on the subject of academic and scientific communication and 
language, since this has applications in the field of educational methodologies.The image (main form of learning today) and the use of simple language are a challenge in the construction of a scientific culture

Specialised learning in each of the academic subjects and correct use of what has been learnt (through speech and language) forms the basis of the promotion of a scientific culture. This culture, rather than being based on a dialogic culture with opposing sides, is based on a socialising culture, as expressed by Rojas and Caramaco (2009, p. $24)^{19}$. It seems that the possession or not of a structured range of specialised concepts separates students in the same year into two different categories: those who possess this and those who do not. Students who do not identify with a relatively sophisticated academic corpus are unable to construct new theories or devise innovative approaches. Consequently, not only are they unprepared for the exercise of their profession but they also occupy a disadvantaged position with respect to the others. Every discipline has an elaborated terminological apparatus, but there are students in all subjects who only use a very restricted academic code. In the case of students on teacher training degree courses, this problem suggests a bleak future for their future pupils: primary school children. Since the level of comprehension required for entry is not high (only a low average mark is necessary for access to teacher training in Spain), or because these students find it difficult to follow an argument based on academic terminology, their university teachers employ more basic terminologies characterised by simple analogies. Consequently, their students cannot formulate new proposals because these would be based on new contributions or advanced studies, as we shall see later.

There is evidence of errors in writing and speech, minority use of elaborated language and excessive use of visual materials in teaching, which are employed as analogies to define concepts, leading to a loss of the capacity for analysis. The widespread use of more visual analogies that lack scientific content has transformed and shaped higher education institutions. Language is losing its analytical content in these centres.

This further polarises the restricted/elaborated code discrepancy among students, widening the gap between those who identify with their teacher and those who do not. This will undoubtedly influence the future state of science among students and teachers alike. It should be borne in mind that teaching staff will obviously produce further research and studies, and these will reflect the typical features of the prevailing academic status at the time (their rationales and the questions posed will depend on the everyday environment).

The importance of this topic will depend on the type of education or area in question. However, it is contradictory that students who intend to work in early education (future primary school teachers) should be experiencing these basic difficulties.
We must ask ourselves if the problem is limited to young people and what we as teachers in higher education can do, what new strategies or tools could be used to effect a change and instil codes with the capacity for analysis and construction of theory. One possibility is to use a methodology based on specialised conceptual maps. In each class, students can and should be required to give accurate definitions of the descriptors that have previously been explained to them. This is related not only to the teaching medium of communication, but also to the design of tasks and methods aimed at rectifying these deficiencies. One explanation for these striking results may be that teachers do not feel responsible for remedying students' language and terminology deficiencies because they consider this to be outside the scope of their duties or subject matter. Other issues highlighted by the present study include the need for continuing professional development for teaching staff to prevent the impoverishment of highly scientific terminology and therefore the dwindling analytical and scientific use (researchers) of important terms or concepts in each subject or field of study.

A high percentage of students believed that possessing a command of the scientific terminology associated with a subject was related to the construction of new theoretical and practical models. However, they perceived learning specialised terminology to be relatively unimportant as regards scientific construction. They were unclear as to who was ultimately responsible for the correct elaboration and expression of their discourse, but indicated the need for a suitable method to develop a more elaborated code (competencies related to terminology and concepts in the subjects taught). This is something that teachers to date had not implemented in their subjects.

Although these higher education students did not possess a command of specialised academic codes, paradoxically there is a pressing need in science today to reach out to the public, know how to communicate better and achieve reliable rates of implementation. Classes must impart academic content that forms the basis for developing capabilities that are socially essential for students, specialised constructions related to the profession and an innovative grasp of the same beyond the classroom, the faculty and the institution.

The present analysis suggests a pressing need to incorporate specialisation seminars in accordance with curriculum, because there is a relationship between the effects observed, on the one hand, and current communication via electronic devices and the use of social media on the other. Most of the students confirmed that their frequent errors in spoken and written language were due to the use of technological media. As has been the case for subjects such as interculturality, immigration and gender, a cross-curricular approach should be adopted to teach students about the media and help them develop strategies to avoid incorrect use of language. 
Advances in knowledge depend on the correct use of specialist or academic terminology because the development of creativity and the formulation of new theories rely on the acquisition of a specialised culture and terminology. It should also be borne in mind that besides scientific knowledge, there are other forms of knowledge without which science would never have existed (González Arias, Rosario, 2017) ${ }^{20}$, because knowledge is everything we have collectively understood and assimilated; that which is culturally constructed based on a series of individual and shared life experiences.

For the construction of knowledge, communicative interaction can be transformed into interpersonal knowledge if mental models are shared (Leal Ladrón de Guevara, p.57) ${ }^{21}$. This requires the interrelationship of cognisant subjects with the aim of acquiring knowledge, a construction in which several actors participate. In this case, the models are of an academic nature, but the interrelationship between students who share a non-academic discourse exerts a greater influence and affects their education because university professors adapt to this simpler style of speech in order to be understood by their students. Education is always based on communicative interaction and is partially responsible for these deficits, not only in scientific construction but also in the construction of scientific culture.

\section{Acknowledgements}

I thank the students for allowing me to delve more deeply into the results and design questionnaires for the good of all.

\section{APPENDIX}

\section{Questionnaire administered to students}

$$
\begin{gathered}
\text { Sex* } \\
{ }_{\mathrm{M}}^{*} \\
\mathrm{~F}^{\mathrm{F}}
\end{gathered}
$$

Age*

Between 18 and 20 years old

Between 21 and 23 years old

Between 25 and 27 years old

_Over 27

Please state your prior education:

1. Do you think you have problems regarding the correct use of language? *

In general, yes

In general, no
2. Do you think that ensuring the correct written and spoken use of language *

Is the responsibility of teachers?

_Is not the responsibility of teachers?

_Is only partially the responsibility of teachers?

_Is the responsibility of parents?

_Is the responsibility of each student?

3. Regarding the correct written use of language, would you say you are *

_Not very satisfied?

_Completely satisfied?

_Very satisfied?

4. How do you think mistakes in the written and spoken use of language should be corrected? *

By giving a lower mark

By giving a verbal explanation

_Other (please specify):

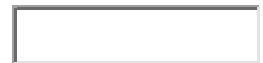

5. $\quad$ The use of incorrect language *

Hinders the construction of new knowledge

Hinders scientific academic construction

_Hinders correct assimilation of subject matter

6. Where do you think the learning and correct use of written and spoken language is most important? *

In teacher training faculties

In humanities and arts faculties

- In higher education for communicators, journalists, writers and languages

__In all types of higher education

_At all educational levels

7. Do you think that an average use and level of spoken and written language is related to: *

_A higher education?

_An appropriate education?

_A medium level education?

_. A scientific education?

_Other

8. Do you think that proof of incorrect use of language implies lack of understanding of questions at a higher academic level? *

-Yes

No

9. Do you think that learning to use academic language is: *

Important?

Essential?

Suitable for medium level and higher education?

Useful but not essential for education? 
10. Have your teachers designed strategies to improve language use and writing skills? *

Yes No

11. When do you think that evidence of incomprehension of terms and incorrect use of language is most apparent? *

In examinations

__In daily relations with students

_In spoken language in class

Other:

12. Do you think that having a command of the scientific terminology of each subject is vital for students' knowledge of the subject matter? *

Y Yes

_Only in order to understand the subject matter _No

13. Do you think that a student's command of the scientific terminology of the subject matter bears any relation to the creation and construction of new theoretical and practical models? * No

_Yes

_-Only for the creation of new theoretical models

_Only for the creation of new practical models

14. Is a specific methodology used in class to acquire competencies related to learning the specialised terminology of the subject matter taught? *

-Yes

No

15. Do you think that the correct use of spoken and written language bears any relation to the skills of scientific observation? *

-Yes

- No

_Only in part

16. Do you think that your own mistakes in language use are due to *

-The use of youth slang?

_ The little importance given to language use in general?

_ The customary use of modern technologies?

_Other:

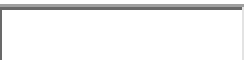

17. Spelling mistakes are *

_Very common among your classmates

Very rare among your classmates

Normal among classmates of this age

_More common than before
18. Correcting errors and mistakes in written language is (you may select more than one option)*

- The responsibility of teachers

— The responsibility of institutions

—The responsibility of parents

_ The responsibility of the individual in question

*Answering these questions is obligatory

\section{REFERENCES}

[1] The observations referred to in this study were conducted in the Faculty of Education at the University of Cadiz (Spain).

[2] Pérez-González, A. B. Imperfect Language. In: Proceedings of $4^{\mathrm{a}}$ International Science and Tecnology Conference. Sakarya Rome: University Organizes ISTEC; 2013. p. 939-948

[3] Montero Martínez, S. Estructuración conceptual y formalización terminográfica de frasemas en el subdominio de la oncología. ELiES;[on line]. 2003[accessed 26/01/2019]; vol 19. Retrieved from: http://cort.as/-EC-t

[4] Hymes, D. The ethnography of speaking. In T. Gladwin and W.C. Sturtevent (eds). Anthropology and Human Behavior. Washington, D.C:Anthropological Society of Washington.1962. p. 13-53.

[5] Byram, M. Cultural awareness as vocabulary learning, Language Learning Journal. 1997;(16): 51-58.

[6] López Pérez, M. V. Cuestiones relativas al léxico de la lengua de instrucción para su enseñanza en español L2 para inmigrantes Proceedings of ASELE. ACTAS XV. Centro Virtual Cervantes p. 334- 541.

[7] Christ, H. Palabras clave de civilización en le clase de idiomas. In Segoviano, C., ed. La enseñanza del léxico español como lengua extranjera. Vervuert, Iberoamericana; 1996. p. 290- 298.

[8] Gumperz, J. The speech community. In International Encyclopaedia of the Social Sciences. London: Macmillan;1968.

[9] Cabré, M. La Teoría Comunicativa de la Terminología, una aproximación lingüística a los términos. Revue française de linguistique appliquée [on line]. 2009 [accessed 26/01/2919]; vol. XIV (2): 9-15. Retrieved from: http://cort.as/-EAHc

[10] Op. cit. p. 199.

[11] Cabero, J. and Gisbert, M. La formación en Internet. Guía para el diseño de materiales didácticos. Sevilla: MAD-Eduforma-Trillas; 2005

[12] Toschi, L. La Comunicazione Generativa. Milan: Ed. Apogeo; 2011

[13] It is beyond the scope of the present paper to discuss this aspect in greater depth. For a more detailed study of youth and the media, see Salzano D., and D'Antonio V. We don't need no education. Repensar la educación en la era de los medios sociales. Revista Hachetetepé [on line]. 2015 
[accessed 26/01/2019] (11): 79-90. Retrieved from: http://cort.as/ySy0

[14] Payán Sotomayor, P. M. El habla de Cádiz. Cádiz: Quórum eds. 2000. A summary of the traits defined and written by the same author.

[15] McLuhan, M. Gli strumenti del comunicare. Mass media e società moderna. Milano: Ed. Net; 200216. Hymes, D. Models of the interaction of language and social setting, Journal of Social Issues.1967; 23 (2): 8-28.

[16] Willis, P. Producción cultural y teorías de la reproducción. Educación y sociedad. 1986; 5:7-34

[17] Bernstein, B. La estructura del discurso pedagógico. Clases, código y control (vol. IV) España: Ed. Morat; 2001.

[18] Rojas A, C. and Caramaco, Z. Formación Docente, el Lenguaje Oral y los programas informáticos. Kaleidoscopio. 2009; 06(12):21-32

[19] González Arias, R. Epistemologías y Pedagogías (Modulo) Curso Miradas para la Paz MZC [on line] 2017 [accessed 26/01/ 2019]: Retrived from: http://cort.as/-EC3C.

[20] Leal Ladrón de Guevara, A. Introducción al discurso pedagógico Horizontes Educacionales 14, (1): p.51-63 [on line].2009 Universidad del Bio Bio, Chile. [accessed 30/10 2018]. Retrieved from: http://cort.as/-EC8V 